\title{
Cooperative Classroom: How to Best Prepare New Generations for the $21{ }^{\text {st }}$ Century Practice
}

Dagmar Sieglová

Škoda Auto University, Czech Republic

\begin{tabular}{|c|c|}
\hline & ABSTRACT \\
\hline $\begin{array}{l}2016 \text { Research Leap/Inovatus Services Ltd. } \\
\text { All rights reserved. } \\
\text { DOI: } 10.18775 / \text { jibrm.1849-8558.2015.53.3002 } \\
\text { URL: } \underline{\text { http://dx.doi.org/10.18775/jibrm.1849- }} \\
\underline{8558.2015 .53 .3002}\end{array}$ & \multirow{2}{*}{$\begin{array}{l}\text { The dramatic development of communication technologies and media brings new challenges to } \\
\text { education. With easy access to information, students in the globalized world are adopting new } \\
\text { approaches and habits in the ways they manipulate data and content. Traditional methods } \\
\text { represented by mediating information through frontal teaching are no longer efficient, as they } \\
\text { seem unable to develop adequate skills to organize, critically evaluate, and use accessible } \\
\text { content. They also fail to prepare students for professional performance. It is also unlikely that the } \\
\text { students or the social trends would adjust to the old frameworks. Education at macro as well as } \\
\text { micro level needs to acknowledge this reality, and seek new, functional approaches to teaching } \\
\text { and learning. Research shows that the growing amount of information easily available through } \\
\text { modern technologies and media cause split attention and shortening of the attention span in } \\
\text { students. At the same time, the students face an increased demand on advanced skills in reading } \\
\text { comprehension, critical analysis, and reflection in spoken and written interaction. This paper } \\
\text { argues that cooperative learning methods are an ideal tool to deal with large quantities of } \\
\text { information through natural human interaction and best prepare for professional performance. } \\
\text { By maximizing social encounters in pairs, teams or groups, the approach provides ample } \\
\text { opportunities to form and refine opinions, boost critical thinking, and develop communication } \\
\text { skills. In educational setting, the methods help maintain students' attention by actively and } \\
\text { consistently involving all participants, as well as prepare them for natural working dynamics in } \\
\text { their future practice. As such, they represent an ideal tool to develop key competences for both } \\
\text { academic and professional success, reflecting the conditions and needs of the } 21 \text { st century. The } \\
\text { text explains the fundamentals and basic categories of the cooperative learning methods and } \\
\text { outlines, for their implementation in education. }\end{array}$} \\
\hline $\begin{array}{l}\text { Keywords: } \\
\text { Social media, Digital marketing, Online } \\
\text { branding, Millennial }\end{array}$ & \\
\hline
\end{tabular}

\section{Introduction}

The generation gap has probably never been deeper than today. Communication technologies and media of the 21 st century accelerated changes in how people process information, interact, and cooperate across a wide range of areas of the social spectrum. This transformation strongly affects the structure of business practices, entrepreneurship, and thus, the job market. To prepare a successful generation, changes in traditional education are a must. Only a well prepared and trained graduate can succeed in the newly transformed world.

\subsection{The 21st Century Generations}

Professionals from various fields such as sociology, psychology, or business, identify cultural generations to better develop and implement proper communication strategies into their practices. Today's tertiary education students fit into the definition of the so-called generation $\mathrm{Z}$, as it is best described in the field of marketing (Geck 2007, Brončeková 2010, Bershidsky2014, Segran 2016). This generation includes individuals born past 1995, i.e. fully into the time of digital technol ogies. They typically use modern communication tools as a natural part of human life, and are recognized for their higher adaptability to new situations, but rather impaired concentration.

Digital technologies and social media, thus, are also becoming a new reality in education. Students use them to find information or expand their knowledge within the area of their interest. They consult them in search of solutions to problems and study, or work tasks. They turn to them for ideas, or inspiration. They employ them to stay in contact with their wide social networks. They play with them to fill in idle moments or when bored. They hide behind them when feeling insecure or to avoid direct contact with people. They mobilize 
them for quick answers or solutions. Digital technologies in lessons are unfathomable. One never knows when students do or do not use them for the purpose of the lesson.

Generation changes bring along a series of challenges for educators. It has been believed that digital technologies help develop the ability to multitask, i.e. to manage more than one activity simultaneously. Multitasking, however, is questionable when it comes to learning. According to Linda Stone (1998), multitasking, motivated by higher productivity, assumes mechanical actions rather than thinking. In the context of cognitive processes, she defines multitasking as "continuous partial attention", a state of mind when attention is split among multiple tasks. Stone compares this to a state of continual crisis which can be occasionally beneficial for the sake of survival, but is rather problematic when it comes to learning. The limits of multitasking have been discussed in further studies. Using the term "split attention" (Folk 2010, Chabris \& Simons 2010, Strayer et al. 2013), researchers prove multitasking to be possible only in simple, partially automated acts which do not require concentration or mental processing. Multitasking yields more mistakes, tasks last longer and results are perfunctory. Some studies show that split attention may even be a result of anxiety, stress, lack of self-confidence, or limited abilities (Sternberg \& Sternberg 2012).

It is also believed that the unlimited access to information and social contact through media negatively affects concentration. Marketing research professionals studying consumer behavior refer to the results of a Canadian research conducted by Microsoft, which observed a considerable shortening of the attention span in the young generation between 2000 and 2016 (Spaden 2015, Egan 2016). Similarly, Sparks \& Honey marketing agency (2017) points out a rising number of ADHD syndrome diagnoses from 2003.

From the perspective of learning, the unfettered access to data presents a risk of wrong study habits. The students, in search for quick and easy answers, tend to adopt existing frames or others' opinions instead of developing own solutions, and they lack critical evaluation. Quantity frequently outweighs quality. Students get quickly overwhelmed with the content which limits knowledge retention.

The information boom also changes the hierarchy of the teacher-student relationship. The teacher and the course textbook are no longer the only source of content. Educators may experience great gaps in initial knowledge within a single group of students. Occasionally, some students may outperform not only their peers, but even the teacher. This requires a revised approach to teaching if we want to prevent the loss of attention or interest, and retain the teacher's authority.
One must keep in mind that the technological development is a product of the previous generations, not the students themselves. Therefore, the search for new approaches to teaching must be conceived as a shared responsibility. Professionals can no longer develop their methodologies in isolation if they want to find functional solutions to education.

\subsection{Needs Analysis}

Like the field of marketing which bases their new product and service development on up-to- date research of individual customer segment needs, the field of education needs to redesign teaching with the students in mind. Therefore, a needs analysis was conducted at Škoda Auto University in 2016 (Sieglová, Stejskalová \& Giurgiu 2017) to identify areas for change. 72 students from the Business English master's degree programs aged 22 to 26 participated in the study. They completed a questionnaire conducted to redesign curricula and lessons to better prepare students for their future practice. Through closed questions and open narratives, the students described their needs in skills and competences as well as their preferences and expectations regarding the organization of the lessons, including the style of teaching, interaction, cooperation, and class set-up.

The study first focused on the student's communication competence self-assessment. While $51 \%$ of the respondents assessed their language skills excellent or good, $49 \%$ saw them only as satisfactory, not very good, or poor. Among the competences most needed for improvement then, $60 \%$ related to active vocabulary and speaking. Students also saw speaking activities as a priority for lessons in $59 \%$ of the responses, namely conversation, discussions, dialogue, interacting, presenting, negotiation, communication, and socializing.

In the narrative section of the survey, the students described their ideal lesson. While some responses preferred the student and teacher dialogue (e.g. "my ideal classroom will be interacting with the teacher", "I prefer speaking student/teacher 50-50\%"), group work preference prevailed (e.g. "team work and role plays are always the most effective and useful, give more understanding", "every one of us would have a specific role and would have to defend his (her) interest", "work in groups, discussions", "learning in games", "interactive activities", "group conversation leading by the teacher", "interactive, based on developing professional communication and self-presentation skills", "I like group work during the class"). Students also expressed a desire to work with practical materials and tasks (e.g. "a lot of conversation about diverse topics, topics from the business and professional world but also topics from the everyday life connected to politics", "use real life examples and discuss", "small groups talk about actual topics", "learn through solving the problems through discussions", "speaking about current problems", "vocabulary and interesting topic and then talk about this at lesson", "the most important is speaking and 
solving some problems", "model situations such as job interview", "maybe to give teams some case studies, or points of view which they should defend", "only life conversation, discussion. Let it be an active dispute, there should be some conflict or a controversial point of view, which will push everyone to speak. There should be business cases, some problems which team should solve", "I also prefer solving more practical tasks than theoretical problems", "to solve some problematic topic relating to real enterprises (factory, firm)", "prepare to good communication with colleagues, suppliers").

The narratives describing the student-teacher role reveal a desire to become more active participants in lessons ("students should actively participate", "emphasis on the role of student is very important", "student is active participant of dialogue"). The teacher was frequently described as a moderator who "agitates" or "activates" rather than "teaches" ("teacher should be like a moderator, judge, will help to express", "teacher should create interesting, creative tasks for students, which will wake them up", "the role of the teacher would be as a moderator of the discussion and feedback provider", "teacher should not have long monologues", "teacher more of a facilitator, guide").

The accent on active role, practical application of knowledge and skills, group work, communication, interaction, and cooperation indicate that the current time students see education as preparation for their future practice in a social setting, realized through communication acts and active interaction. The following text builds on this premise. It explains cooperative forms of teaching which, according to the author, best reflect the specific needs of the 21 st century education.

\subsection{Cooperative Learning}

Learning has been recognized as a product of socialization and cooperation ever since Vygotskij (Costa 1992). People use knowledge, skills, and opinions to build social networks, exchange views, develop ideas, and search for solutions together. Through social encounters, they gain experience and test it in practice. They challenge, negotiate, and form their opinions, and ultimately, retain, and transmit knowledge.

Cooperative learning is an educational concept which believes that permanent retention of knowledge and skills is possible only through cooperation. Being dynamic and unpredictable, and thus intellectually challenging (Ross and Smyth 1995), cooperation allows to fully activate human cognitive functions. Explained through Bloom's taxonomy of educational objectives (Bloom 1956, Anderson \& Krathwohl 2001, Steel et al 2007a), cooperative learning reaches beyond lower order thinking which includes rather mechanical cognitive processes of knowledge, comprehension and application, and engages the upper order thinking functions including analysis, synthesis, and evaluation that are fundamental for critical thinking.

Cooperative learning is further described as shared efforts built on the principles of cooperation, competition and individual aspirations. Individual participants connect through a common goal, shared responsibilities, and equal chances for success. Attained knowledge, experience, and skills are not seen as the ultimate goal of education but as a direct product of interaction and cooperation (Johnson \& Johnson 1999, Johnson \& Johnson 2009).

The cooperative learning methodology is described as a system of varied techniques that ensure cooperation in varied formats and sizes. These range from pairs, mid-size groups, to large gatherings, allow for creative use of spatial means, and can be implemented within or outside traditional classrooms (Steel 2001, Steel 2007b).

The methods as such respond to the above-mentioned students' needs. They ensure active involvement of all students in parallel working processes, which also eliminates attention splits even in larger groups. They allow the teacher to abandon the traditional frontal teaching style and rewrite the student-teacher relationship into a partnership. While the central role shifts to the students, the teacher as a mediator, provides supervision, support, and organizes activities. The students take over a large portion of responsibility for their own learning. Cooperative learning methods also optimize teaching as they enable to work effectively with diverse topics and varied materials. Teams can be formed by interest, expertise, or task complexity. Life materials can be flexibly incorporated in lessons; up-to-date topics are being covered. When students cooperate, ultimatelly, they naturally develop their key communication and study competences. In social encounters, students talk to each other to clarify meanings, contrast their ideas, and form their opinions. Live discussions enforce spoken communication competences, along with active listening. The work with ideas and opinions in social contact refine critical thinking.

Cooperative learning represents an inspiring, creative, and stimulating concept with a pragmatic reach. It contributes to effective and sustainable retention of knowledge and motivates for further learning. The ultimate result is an active, critically thinking and concentrated student. The following text illustrates varied forms of cooperative learning, describes their character and function, and suggests their application within the educational context.

\section{Cooperative Learning Techniques}

Cooperative learning techniques divide into four categories according to the number of participants, format, and role distribution within and outside the units. The four categories involve pairs, variable groups of smaller formats, specialized teams, or whole class gatherings. 


\subsection{Pair Work}

People frequently work in two to share a mutual task or help each other, or they provide each other feedback or guidance. Likewise, pair work represents the basic unit for cooperation in the classroom. Pairs are usually formed according to the sitting position or by any other criterion. Work in pairs involves direct cooperation on a shared task, or exchange of solutions from previous individual work. Pair work helps activate all participants simultaneously. These activities are easy to organize and do not require specific spatial conditions. Pair tasks often serve as preparation for more complex activities.

A popular pair activity is peer brainstorming, a spontaneous discussion used to share or collect ideas for a given topic. Brainstorming is mostly spoken, but can be combined with recording notes. Peer brainstorming prioritizes quantity before quality as it primarily aims at generating a wide range of ideas. Discussions must take place in a safe and free environment, but should be challenged or corrected in terms of language by others or the trainer.

A second form of pair cooperation is peer reading. It is a method that facilitates text comprehension in cooperation with a partner. Couples share the material split in short sections, ideally paragraphs, and study them in sequences. For each section, they may agree on key ideas, keywords, or entitle them. This technique is also a very effective peer study method beyond the classroom.

An alternative to peer reading is reading through questioning. It is based on reading a text in pairs, paragraph by paragraph, through questions. For each section, both partners formulate questions to each other to which the answer is contained in the text. They can also split and alternate roles, one partner prepares the questions, the other studies the section to be able to answer them. A more challenging alternative is to hide the text when answering the partner's questions from memory.

Another method is mirror reading. Each pair receives the same text in two versions, one with blank spaces for odd, and the other for even paragraphs. Partners read through the text filling the missing sections by summarizing the missing section for each other in their own words.

Pair work can also be applied to listening activities. The best way to manage peer listening is to share or divide roles. Both students may either pursue the same task and then compare their solutions, or work on a mutual goal by splitting roles and compiling their solutions afterwards. For example, one partner takes notes while the other listens and concentrates on remembering, then, they reconstruct the content together. One searches for key words, the other for main ideas. One focuses attention on one side's arguments, the other on the opposing ones. One focuses on one participant in the speech, one on the other.

The most difficult pair work technique is peer writing. Peer writing does not mean compiling pieces into a single text, but is a highly interactive process. Partners jointly agree on the topic, goal, structure, and strategy. During the writing process they align ideas, content, and the style of writing. They do not omit the final revision. Ideally, shared writing is done directly inlessons with active guidance of the teacher.

Peer editing, finally, means mutual evaluation of individually written texts. Instead of corrective feedback from the teacher, often ineffective, students themselves take over the teacher role. Clearly set evaluation criteria for structure, language form, vocabulary, or terminology are necessary. Feedback must be emotionally neutral and factual.

\subsection{Assembled Studies}

Assembled studies reflect the versatile character of human cooperation. They are organized through small group formations that change and combine participants within teams throughout the process. Teams change as the students visit expert and home groups to process and compile knowledge or information. Assembled studies enhance student active involvement in the learning process, individual responsibility, and concentration. Students are activated by changing positions between teams. Assembled studies require a more careful teacher preparation and implementation, and they are suitable for analytical work with the content. The interactive and socializing character of individual techniques strengthen student communication skills.

The three-phase dialogue, sometimes also called think-pairshare, is the basic assembled study technique. Students first work individually, then share their results in pairs to further share, present, or develop a solution in cooperation with another pair. Each group of four can work on the same tasks to point out the possibility of different solutions; groups can work on different tasks which get compared with other alternatives to the solutions, or each team can work on a partial task contributing to a common project. The three-phase dialogue is good preparation for more complex teamwork.

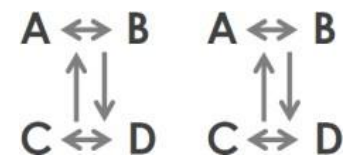

Figure 1: Three-phase dialogue

Blindfold represents a more complicated assembled study technique. It is based on conveying information from two different study resources between two partners and their subsequent assembly in expert teams. Partners first study their material individually, then reproduce the content verbally to their counterparts who listen, ask clarification questions, and 
take notes. After that, students reorganize into expert groups of two or more students to reconstruct the content work of their original partners in cooperation. This method enhances reading comprehension, active listening and speaking skills. The technique is ideal for materials of similar format, accentuating contrast, similarity, or difference.

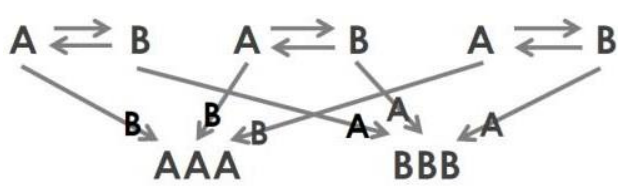

Figure 2: Blindfold

Some stay - some stray (A-BCD) is another combination scheme that is based on the principle of collecting or sharing information between other teams. The basic set-up consists of four teams of four but can vary greatly according to the needs and size of the class. Each team starts to work on an assignment separately. Then, three members of each team distribute into the other three groups to share or collect information. Finally, they return to their original home groups to share new findings or incorporate them into their final solutions.

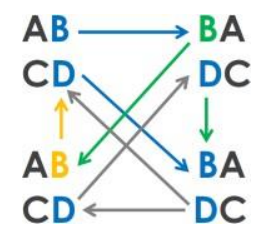

Figure 3: Some stay - some stray

Teams can vary as needed. In three-member teams, one remains and two rotate $(\mathrm{A}-\mathrm{BC})$, four can also rotate in two (AB-CD); in groups of five one remains and four rotate (A$\mathrm{BCDE})$ or two remain and three rotate $(\mathrm{AB}-\mathrm{CDE})$. This technique develops communication and learning skills; it however requires a very careful organization.

The most complicated technique of assembled studies is jigsaw. It is based on dividing a task into several parts and distributing them to the prospective number of individuals within each team (e.g. $\mathrm{ABC}-\mathrm{ABC}$ ). A task assigned to individual parts of the material is then shared and discussed in reorganized expert pairs (AA-BB-CC). Individual parts are then compiled into a final outcome, back within the home groups $(\mathrm{ABC}-\mathrm{ABC})$.

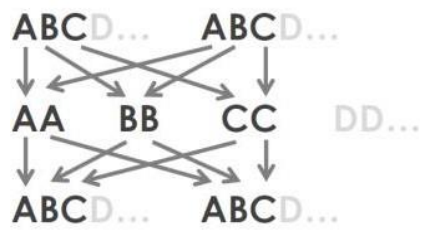

Figure 4: Jigsaw

\subsection{Team Work}

This technique can also be used in varied combinations. The course material can be divided into a corresponding number of parts for each team member, or varied types of resource materials can be used (text, visuals). Expert teams created in the second stage can also be triples or quadruples. The technique is more demanding on coordination, but it is an excellent tool to maximize active involvement of all participants, even in larger groups. It works well with longer texts or when more varied resources covering a topic, are available.

People complete their working tasks in predesigned teams. Team work described in this section is based on fixed groups that remain unchanged throughout the whole activity. Teams work on a task together, while sharing a mutual goal and responsibility for the completion of the task. Team members typically take upon specialized roles, which are either assigned or self-selected according to varied tasks, interests, or capabilities. Roles can also be hierarchical as groups may be guided by a team leader who assigns tasks and monitors the process. Roles may also be based on expertise. Teamwork enhances cooperation and communication skills. It helps simulate reality, and as such, it represents an ideal preparation for practice. Team work is easy to organize and allows for dealing with diverse classrooms.

The basic type of teams is buzz groups. These are groups with no role distribution which can vary in size. Contributions, as well as roles, develop spontaneously. Buzz groups are suitable for brainstorming, they train cooperation and assertiveness.

Another alternative of teamwork is opinion groups. These are formed based on a shared opinion or attitude for which the teams advocate. Opinion groups allow for flexibility in size and are suitable for training argumentation and debates. They help shape opinions and cultivate discussion.

Expert teams finally, consist of specialists within a chosen field, for example, from the business environment (manager, finance expert, human resource manager, marketing specialist), or from politics (minister, president, lobbyist, deputy, senator). The successful completion of the task depends on a well-balanced combination of individual responsibility and cooperation skills. Expert teams enable students to handle complex tasks and are suitable for case studies, projects, or research activities. They help simulate situations from practice.

\subsection{Class Fairs}

Companies and organizations form a complex whole of people who follow the same mission. The aim of class fairs, described in this section, is to provide opportunities for mutual contact with everybody. Their frequent communication unit is usually pairs, which either vary throughout the activity, or gradually grow into larger formations. Class fairs represent a 
very effective cooperative learning method, as they build up knowledge or experience from multiple social encounters. Participants experience a diversity of personal opinions, skills, or interests which strengthens positive relationships, tolerance, patience, respect, the ability to compromise, and cultivated communication. Class fairs are therefore an excellent preparation for practice. They can however, be more demanding on organization and time, and also tend to be noisier as they frequently pose participants involved in simultaneous discussions.

The snowball technique is based on the principle of gradually merging groups of smaller sizes into larger formations. The first contact occurs in pairs, two couples then join into quadruples, and so, the activity continues until the whole group joins into one team. Snowball is suitable for brainstorming, problem solving, or for developing strategies; it is also used to create compilations of ideas, sets of items, or rules. They help reach mutual agreements.

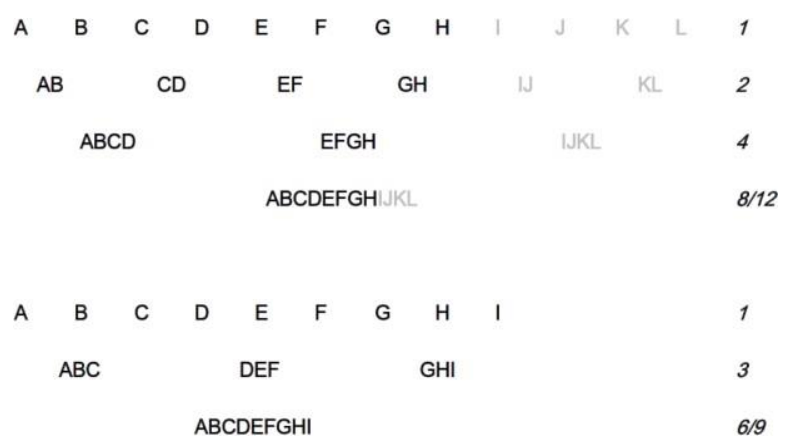

Figure 5: Snowball

The aim of the rounds method is to allow space to every participant to contribute with short presentations, arguments, or ideas to a common discussion. Individual contributions follow a pre-defined sequence or students self-select until everybody takes a turn. Students can also be selected by the teacher which allows for working with different personality characteristics. More audacious students contribute sooner, while others receive more time before speaking. Less concentrated students can be selected later to keep them engaged longer. Individual inputs might be limited in time (e.g. one minute for each), or may be assigned an outline or structure (e.g. one opinion, three supporting arguments, a conclusion). The rounds technique is an excellent tool for training language and presentation skills.

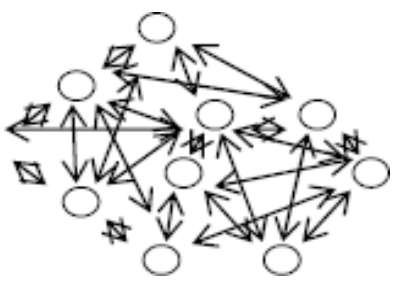

Figure 6: Rounds
Round robin is a technique that involves simultaneous pair interactions, where pairs combine in a free order until every participant pairs with everyone. This technique can be organized in two different formats. The teacher can either prepare a common question while the students discuss their individual answers, opinions, or stances among themselves (e.g. Which country would you like to visit? What personality inspires you? Which profession is the most interesting to you?). This format is suitable for an exchange of varied views on a single topic. Or, the trainer, based on the number of participating students, may compile a corresponding set of questions related to a common topic and assign individual participants to survey answers from their peers. The collected responses then get analyzed in a follow-up activity. This format can be used for varied surveys or opinion polls.

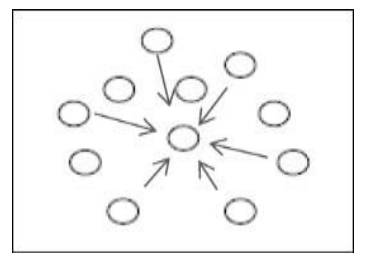

Figure 7: Round robin

The last technique allowing for multiple encounters is called carousel. Students work in pairs organized into an inner and outer circle, making it possible to move one space to the right or left. If circles are not possible, two lines facing each other are also an alternative. Individual couples then work on an assigned task such as arguing on a given topic or conducting an interview. Each pair divides roles: one argues while the other is the opponent, or one is an interviewer and the other an interviewee. When finished, students in each circle (or row) move to the neighboring station in the opposite direction, one circle to the right, the other to the left. The task remains in place. As a result, everyone changes their partner, task, as well as role. This process repeats until everyone returns to their original place, completes all tasks and meets with everyone. This technique is a good tool for practicing argumentation for discussions or job interviews.

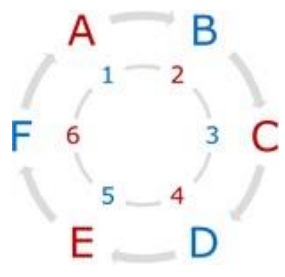

Figure 8: Carousel

\section{Conclusion - Discussion}

Despite the great potential of cooperative learning for the 21st century teaching, it is necessary to discuss potential challenges teachers may be facing when planning their teaching practices. First, cooperative learning presents a new approach to many educators as well as students. Some teachers may be skeptical 
or hesitant. Some students may refuse to accept new forms of learning. The prerequisite for a successful implementation is an open attitude from both sides. The teachers need to be convinced about the benefits of the methods, while the students need time to adapt to the new style of interaction.

Cooperative learning assumes careful teacher preparation and coordination. Each lesson needs to be methodic and each activity prepared in detail. A high degree of flexibility and adaptability on the side of trainers is necessary to properly handle the dynamics of interaction. Some of the techniques require specific space conditions and equipment, to allow for free movement in the space, or change the position of chairs or desks. Enough space for written presentations, such as blackboards or mobile flip-chart stands, and papers are also necessary. Students, on the other hand, must be ready to cooperate, be mutually tolerant and respectful. Cooperative learning also requires a great degree of autonomy and individual responsibility from the learner's side, as it puts high demands on active engagement and initiative in pursuing a common goal.

Although students generally welcome change toward a more active involvement (Sieglová, Stejskalová \& Giurgiu 2016) one cannot expect the approach to suit all. Cooperative learning provides opportunity to engage all participants, so it is generally beneficial for less confident or shy students. A negative attitude, in contrast, can be encountered from more outspoken or dominant personalities who may feel underprivileged in teams. Individualists may feel tied or slowed down. Likewise, students with more advanced knowledge in the subject, language or communication skills can see cooperative learning as tedious. The approach may also be threatening because of the unpredictability and social demands arising from cooperation. Unwillingness to cooperate can also come from a lack of self-confidence, fear of failure, or simple idleness. Educators therefore need to find a balance in their practices to work properly with their students' personal characteristics and individual methods chosen.

Students may sometimes doubt or dispute the measurability of results generated from cooperation and their chances to influence their own study results. For this reason, it is necessary to carefully balance course requirements and activities based on team cooperation with individual work, as well as clearly define the evaluation criteria for both.

Despite the above-mentioned challenges, the advantages of cooperative learning prevail (Tsay \& Brady 2010, Brown \& Ciuffetelli 2009). The approach can be implemented across disciplines and the education ladder. It is especially appropriate for professional areas that assume interaction and communication skills. Sharing and active cooperation create opportunities for communication, negotiation, argumentation, or presentation of own ideas and attitudes. They also maximize individual engagement, motivate for further learning, enforce knowledge and skills, build positive relationships, and cultivate social debates.

Cooperative learning is an excellent tool to implement individual approaches. It allows for great flexibility in building teams and dividing roles tailored to participants in response to individualized criteria or personalities. As an active mediator, the teacher prepares, monitors and directs teaching, provides feedback and individual attention as needed.

Cooperative learning enhances self-development and study skills. For its highly interactive character, it enforces active attention and engagement. At the same time, it strengthens communication and social skills, hence, self-confidence. Students train assertiveness, organization, and management. On a personal level, cooperation cultivates dialogue, helps make decisions, solve problems, negotiate, make compromises, and prevent conflicts. Through active involvement, students take responsibility for their own learning. They exercise both productive and receptive skills, work with varied resources from different media, which they process together toward required outputs.

As such, cooperative learning constitutes excellent preparation for practice. Work in pairs, small or medium sized groups, fixed teams, or in large conferences while pursuing a shared goal reflects well the reality of the job environment. The traditional educational approaches, accentuating knowledge over skill, therefore need to change. It is important to realize that school and higher education consequently, do not prepare future professionals for academic careers but for a much wider range of fields in the labor market. As information is no longer a scarce commodity, it is therefore the competencies related to the ability to process, share, and use it as common knowledge within a social context.

Cooperative learning also presents invaluable potential for society. Students gain self- confidence, learn independence, responsibility, and mutual respect in their pursuits toward common goals. They cultivate discussion, judgments, thereby critical thinking crucial to tackle the current time social challenges. Cooperative learning presents a progressive approach that prepares a generation of personally accountable, actively involved, independent, and critically thinking individuals capable to take over the responsibilities for society and its future at a global scale.

\section{References}

- Bershidsky, Leoni (2014). Here comes generation Z. Available from: https://www.bloomberg.com Bloom, Benjamin (1956). Taxonomy of educational objectives. The classification of educational goals.

- Handbook I: Cognitive domain. New York: David Mc Kay Company, Inc 
- Brončeková, Katarína (2010). X, Y, Z - tři písmena, tři nejvýraznější generace současnosti. Available from: http://www.hrforum.cz

- Brown, H. and D. C. Ciuffetelli (2009). Foundational methods: Understanding teaching and learning. Toronto: Pearson Education.

- Chabris, Christopher and Daniel Simons (2010). The invisible gorilla and other ways our intuitions deceive us. New York: Crown.

- Costa, Arthur (1992). An environment for thinking. In Cathy Collins, John Mangerieri. Teaching thinking: An agenda for the 21st century. Hillsdale: Lawrence Erlbaum Associates, 168-181.

- Egan, Timothy (2016). The eight-second attention span. The New Your Times. Available from:

https://www.nytimes.com/2016/01/22/opinion/t he-eight-second-attention-span.html

- Folk, Charles (2010). Attention: Divided. In E. B. Goldstein. Encyclopedia of Perception. Thousand Oaks, CA: Sage, 84-7. Crossref

- Geck, Caroline (2007). The generation Z connection: Teaching information literacy to the newest net generation. In Esther Rosenfeld a David V. Loertscher. Toward a 21stcentury school library media program. Maryland: Scarecrow Press.

- Johnson, David and Roger Johnson, R. (1999). Learning together and alone: Cooperative, competitive, and individualistic learning. Boston: Allyn \& Bacon.

- Johnson, David and Frank JOHNSON (2009). Joining together: Group theory and group skills. Boston: Allyn \& Bacon.

- McSpaden, Kevin (2015). You now have a shorter attention span than a goldfish. Time. Available from: http://time.com/3858309/attention-spans-goldfish/

- Ross, John. and Elisabeth Smyth (1995). Differentiating cooperative learning to meet the needs of gifted learners: A case for transformational leadership. Journal for the Education of the Gifted, 19, 63-82. Crossref

- Segran, Elizabeth (2016). Your guide to generation Z: The frugal, brand-wary, determined anti- millennials. Available from: https://www.fastcompany.com/3062475/your-guideto-generation-z- the-frugal-brand-wary-determinedanti-millen

- Sieglova, Dagmar, Lenka Stejskalova and Ioana Giurgiu (2017). Optimizing language instruction at the tertiary level: student needs analysis toward educational change. Language Learning in Higher Education. De Gruyter, 413-433. Crossref

- Sparks \& Honey (2017). Meet generation Z: Forget everything you learned about millennials. Available from: https://www.slideshare.net/sparksandhoney/generationz-final-june-17

- Steel, Jeannie, Kurtis Meredith, Charles Temple and Scott Walter (2007a). Rozvíjíme kritické myšlení.

- Příručka II. Praha: Kritické myšlení, o.s. (2007b). Kooperativní učení. Příručka V. Prague: Kritické myšlení, o.s.

- Steel, Jeannie (2001). The Reading and Writing for Critical Thinking Project: A framework for school change. In David Klooster, Jeannie Steel, a Patricia Bloem. Ideas without boundaries: International educational reform through reading, writing and critical thinking. Newark: International Reading Association.

- Sternberg, Robert and Karin Sternberg (2012). Cognitive psychology. Belmont: Wadsworth Publishing. Stone, Linda (1998). Continuous partial attention. Available from: https://lindastone.net/qa/continuous-partial-attention/

- Strayer, David, Joel Cooper, Jonna Turrill, James Coleman, Nate Medeiros-Ward and Francesco Biondi (2013). Measuring cognitive distraction in the automobile. AAA Foundation for Public Safety.

- Tsay, Mina a Miranda Brady (2010). A case study of cooperative learning and communication pedagogy: Does working in teams make a difference? Journal of the Scholarship of Teaching and Learning, 10 (2), 78-89. 